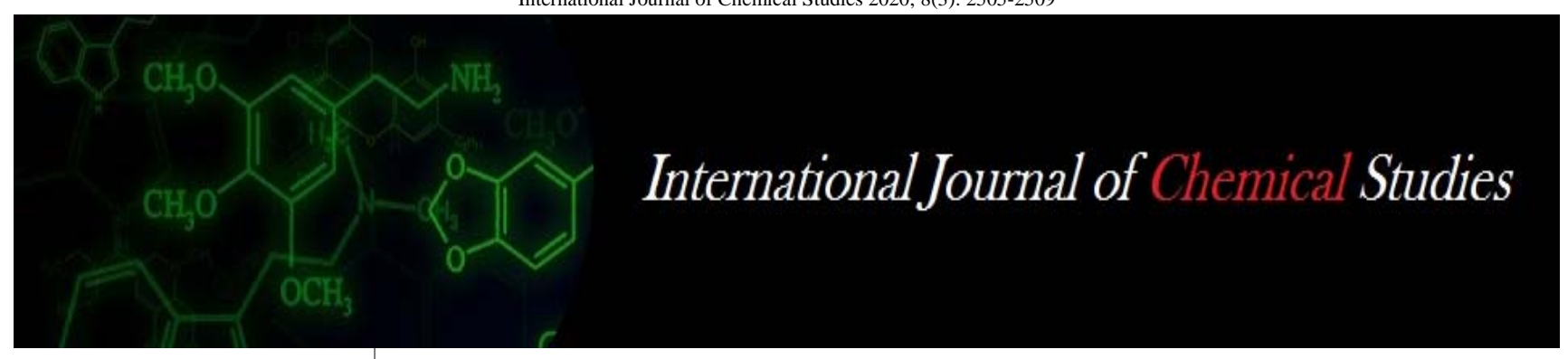

P-ISSN: 2349-8528 E-ISSN: 2321-4902 www.chemijournal.com IJCS 2020; 8(3): 2505-2509 (C) 2020 IJCS

Received: 14-03-2020 Accepted: 17-04-2020

Devendra Kumar Assoc. Professor, PFE, CAE, DRPCAU, Pusa, India

Mohan Singh

Professor \& Head Department of PHP\&FE, JNKVV, Jabalpur,

Madhya Pradesh, India

Shobha Rani

Sr. Scientist \& Head KVK, Jehanabad, Bihar, India

Varsha Kumari

S.M.S. (H.Sc.), KVK, Vaishali, India
Corresponding Author: Devendra Kumar Assoc. Professor, PFE, CAE, DRPCAU, Pusa, India

\section{Effect of material parameters and machine parameters on physical property of extrudates prepared from different blends of sattu and kodo}

\author{
Devendra Kumar, Mohan Singh, Shobha Rani and Varsha Kumari
}

DOI: https://doi.org/10.22271/chemi.2020.v8.i3aj.9587

Abstract

In the present study extrudates were prepared to identify the optimum machine parameters and prepare good quality ready to eat extruded snacks from a suitable blend of sattu and kodo Extrusion aims at producing a voluminous, expanded, crispy product resembling a baked product. The increase in proportion of sattu and die head temperature increases the water absorption index. The water absorption index achieved a maximum value of $58.5 \%$ and a minimum value of $48.7 \%$. The bulk density increases with the increase in moisture content increases in proportion of sattu and the increase in barrel temperature with decrease in die head temperature and increase in screw speed. The bulk density achieved a maximum value of $0.60 \mathrm{~g} / \mathrm{mm}^{3}$ and a minimum value of $0.46 \mathrm{~g} / \mathrm{mm}^{3}$.

Keywords: kodo, extruder, moisture, sattu, millet

\section{Introduction}

Extrusion cooking combines the heating of food raw material with the act of extrusion to create a cooked and shaped food product. Cooking of food ingredients during the extrusion process results in the gelatinization of starch, denaturation of protein, inactivation of many raw food enzymes responsible for food deterioration during storage, the destruction of naturally occurring toxic substances such as trypsin inhibitors in soybeans, and the diminishing of microbial counts in the final product. Humans and other monogastric species cannot easily digest un-gelatinized starch. Extrusion cooking is somewhat unique because gelatinization occurs at much lower moisture levels (12-22\%) than necessary in other food processing operations rather processing conditions that increase temperature, shear, and pressure tend to increase the rate of gelatinization. The presence of other food compounds, particularly lipids, sucrose, dietary fibre and salts, also affects gelatinization (Harper 1981) ${ }^{[1]}$. Extrusion cooking is a high-temperature short-time (HTST) process capable of generating high temperatures up to $200{ }^{\circ} \mathrm{C}$ or so; high pressures up to $2000 \mathrm{psi}$, and relatively high shear rates of 10 to $200 \mathrm{~s}^{-1}$ in extrudes the retention time is sufficient so that each cereal particle achieves temperature and moisture equilibrium. The extruder barrel itself consists of jackets that contain the rotating screws. In the feeding zone, low-bulk-density raw materials are introduced into the extruder barrel. The overall feed rate is limited by the ability of the screws in this section to transport the dry feed. In the compression zone, kneading continues, and the screws of the extruder start to achieve a higher degree to fill as their screw pitch decreases. The raw material loses its granular texture, and its density begins to increase, as does the pressure inside the barrel.

\section{Methods and Materials}

Sattu and kodo were procured from local market. After initial removal of foreign materials, all the mixture of sattu powder and kodo flour) were blended in predetermined proportions and mixed thoroughly in mixer and then they were fed to the Brabender single screw extruder at specific moisture content for making the extruded product at different predetermined set of operations.

Bulk Density

Bulk density is the mass per unit bulk volume where the volume is calculated including the 
volume of void spaces, it was calculated by tapping method. The extrudates were filled in a measuring cylinder of capacity $100 \mathrm{ml}$ and tapped, the extrudates were allowed to settle thoroughly inside the cylinder and when there was no more setting observed further the tapping of the cylinder was stopped and it was weighed and the mass of $100 \mathrm{ml}$ sample was recorded. Now the bulk density was calculated by as:

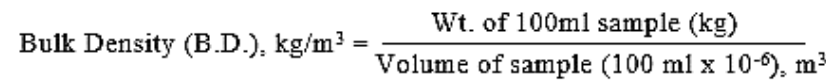

\section{Result and Discussion}

\subsection{Water Absorption Index (WAI) of Extrudates}

The multiple regression analysis for water absorption index (WAI) of extrudates versus feed moisture content $\left(\mathrm{MC}_{\mathrm{F}}\right)$, blend ratio $\left(\mathrm{B}_{\mathrm{R}}\right)$, barrel temperature $\left(\mathrm{T}_{\mathrm{Brl}}\right)$, die head temperature $\left(\mathrm{T}_{\text {Die }}\right)$ and screw speed $\left(\mathrm{S}_{\mathrm{S}}\right)$ was done using CCRD and fitting of second degree polynomial equation for representative response surface of data resulted in the development of following model;

W.A.I. $=285305-1.53 \times \mathrm{MC}_{\mathrm{F}}-29.85 \times \mathrm{BR}-49.10 \times \mathrm{T}_{\mathrm{brl}}+$ $26.87 \mathrm{~T}_{\text {die }}-11.54 \times \mathrm{SS}+0.65 \times \mathrm{MC}_{\mathrm{F}} \times \mathrm{BR}+0.59 \times \mathrm{MC}_{\mathrm{F}} \mathrm{x}$ $\mathrm{T}_{\text {brl }}-0.53 \times \mathrm{MC}_{\mathrm{F}} \times \mathrm{T}_{\text {die }}+0.30 \times \mathrm{MC}_{\mathrm{F}} \times \mathrm{SS}+0.01 \times \mathrm{BR} \times \mathrm{T}_{\text {brl }}$ $+0.13 \times$ BR $\times \mathrm{T}_{\text {die }}+0.04 \times$ BR $\times$ SS $-0.13 \times \mathrm{T}_{\text {brl }} \times \mathrm{T}_{\text {die }}+0.04$ $\mathrm{x} \mathrm{T}_{\text {brl }} \times \mathrm{SS}+0.04 \times \mathrm{T}_{\text {die }} \times \mathrm{SS}-1.90 \times \mathrm{MCF}^{2}-0.08 \times \mathrm{BR}_{2}+$ $0.21 \times \mathrm{T}_{\text {brl }^{2}}-0.04 \times \mathrm{T}_{\text {die }^{2}}-0.04 \times \mathrm{SS}^{2} \quad \ldots 3.1$

The $\mathrm{R}^{2}$ had a value of 0.7009 for the model. The brief information are presented in Table 1

The standard deviation, coefficient of variation, mean and predicted residual error sum of square (PRESS) values, coefficient of determination and predicted $\mathrm{R}^{2}$ and adequate precision are given in Appendix- $\mathrm{H}$.

The response surfaces developed from the model 4.5 are presented in Fig. 3.1 to 3.10. Response surface graphs Fig. 3.1, 3.2, 3.3 and 3.4 show the interactive effect of moisture content of feed with blend ratio, barrel temperature, die head temperature and screw speed respectively on water absorption index of extrudates. Fig 3.5, 3.6 and 3.7 show the effect of blend ratio with barrel temperature, die head temperature and screw speed respectively on water absorption index of extrudates. Fig. 3.8 and 3.9 show the interactive effect of barrel temperature with die head temperature and screw speed respectively on water absorption index of extrudates and Fig. 3.10 shows the response surface graph of die head temperature and screw speed on water absorption index of extrudates.

It is seen from Fig. 3.1, 3.2, 3.3 and 3.4 that by decreasing the moisture content of feed and increasing the die head temperature and screw speed and blend ratio, the value of water absorption index increases and vice-versa, while barrel temperature did not affect-much the value of water absorption index. Fig. 3.5 and 3.6 show that the maximum value of water absorption index lies at $190{ }^{\circ} \mathrm{C}$ die head temperature and 40:60 blend ratio beyond which the value of water absorption index decreases. As the barrel temperature increases the water absorption index increases slightly. High barrel temperature must be causing the evaporation faster thereby increasing the bubbles and air pockets which absorbs moisture when soaked. Fig. 3.7 shows the interactive effect of blend ratio and screw speed on water absorption index. By increasing the value of blend ratio and increasing the screw speed up to $120 \mathrm{rpm}$, the water absorption index gradually increases. Fig 3.8 shows that with increasing in barrel temperature, the die head temperature the WAI increases slightly. Fig. 3.9 shows that the value of screw speed increases keeping barrel temperature at constant level the water absorption index increases.
In the figure 3.10 the maximum value of water absorption index lies nearly at $200{ }^{\circ} \mathrm{C}$ die head temperature and about $120{ }^{\circ} \mathrm{C}$ barrel temperature. After that by increasing any one parameter, will increase the water absorption index while simultaneous increase in both die head temperature and screw speed increases the value of water absorption index.

\subsection{Bulk Density (BD) of Extrudates}

The multiple regression analysis for bulk density (BD) of extrudates versus feed moisture content $\left(\mathrm{MC}_{\mathrm{F}}\right)$, blend ratio $\left(B_{R}\right)$, barrel temperature $\left(T_{B r l}\right)$, die head temperature $\left(T_{\text {Die }}\right)$ and screw speed $\left(\mathrm{S}_{\mathrm{S}}\right)$ was done using CCRD and fitting of second degree polynomial equation for representative response surface of data resulted in the development of following model;

B.D. $=-14.08+0.08 \times \mathrm{MC}_{\mathrm{F}}-0.04 \times \mathrm{BR}+0.13 \times \mathrm{T}_{\text {brl }} 0.07 \mathrm{~T}_{\text {die }}$ $+0.00 \times \mathrm{SS}+2.20 \times \mathrm{MC}_{\mathrm{F}} \times \mathrm{BR}-1.07 \times \mathrm{MC}_{\mathrm{F}} \times \mathrm{T}_{\mathrm{brl}}+2.32 \times$ $\mathrm{MC}_{\mathrm{F}} \times \mathrm{T}_{\mathrm{die}}-0.00 \times \mathrm{MC}_{\mathrm{F}} \times \mathrm{SS}-8.15 \times \mathrm{BR} \times \mathrm{T}_{\mathrm{brl}}+8.81 \times \mathrm{BR}$ $\times \mathrm{T}_{\text {die }}+2.20 \times \mathrm{BR} \times \mathrm{SS}-2.08 \times \mathrm{T}_{\text {brl }} \times \mathrm{T}_{\text {die }}+6.43 \times \mathrm{T}_{\text {brl }} \times \mathrm{SS}+$ $3.57 \times \mathrm{T}_{\text {die }} \times \mathrm{SS}-2.15 \times \mathrm{MCF}^{2}+1.30 \times \mathrm{BR}^{2}-3.21 \times \mathrm{T}_{\mathrm{brl}^{2}}{ }^{2}$ $1.46 \times \mathrm{T}_{\mathrm{die}^{2}}-2.71 \times \mathrm{SS}^{2}$ ...3.2 The $\mathrm{R}^{2}$ had a value of 0.5576 for the model, the brief information are presented in Table 2 . The standard deviation, coefficient of variation, mean and predicted residual error sum of square (PRESS) values, coefficient of determination and predicted $\mathrm{R}^{2}$ and adequate precision are given in Appendix-H.

The response surface graphs of the model 4.6 are presented in Fig. 3.11 to 3.20. Fig. 3.11, 3.12, 3.13 and 3.14 show the interactive effect of moisture content of feed with blend ratio, barrel temperature, die head temperature and screw speed respectively on bulk density of extrudates. Fig 3.15, 3.16 and 3.17 show the effect of blend ratio with barrel temperature, die head temperature and screw speed respectively on bulk density of extrudates. Fig. 3.18 and 3.19 show the interactive effect of barrel temperature with die head temperature and screw speed respectively on bulk density of extrudates and Fig. 3.20 shows the response surface graph of die head temperature and screw speed on bulk density of extrudates. As seen from the graphs, the bulk density decreases with the decrease in proportion of sattu and the moisture content of feed did not affect much on the bulk density (Fig. 3.11 and 3.12). Whereas the bulk density decreases with the decrease in barrel temperature and with decrease in die head temperature, the bulk density of extrudates decreases (Fig. 3.13). The Fig. 3.14 shows the curvilinear effect of screw speed and moisture content on bulk density of extrudates, which gives the minimum value of bulk density at the centre. It is also observed that the bulk density decreases with the decrease in barrel temperature and blend ratio, whereas has no effect with increase in die head temperature but as the screw speed increases there is decreases in bulk density.

Table 1: Analysis of variance for water absorption index (WAI) of extrudates

\begin{tabular}{|c|c|c|c|c|c|}
\hline Source & DF & SS & MSS & F & P \\
\hline Regression & 20 & 52252.24 & 2612.61 & 1.28 & 0.34 \\
\hline Residual & 11 & 22297.76 & 2027.06 & & \\
\hline total & 31 & 74550.00 & 4639.67 & & \\
\hline
\end{tabular}

Table 2: Analysis of variance for bulk density of (BD) extrudates

\begin{tabular}{|c|c|c|c|c|c|}
\hline Source & DF & SS & MSS & F & P \\
\hline Regression & 20 & 0.12 & 0.006 & 0.693 & 0.770 \\
\hline Residual & 11 & 0.09 & 0.009 & & \\
\hline Total & 31 & 0.21 & 0.015 & & \\
\hline
\end{tabular}




\section{Appendix-H}

Table 3: The standard error, mean, coefficient of variation, predicted residual error of sum of squares (PRESS), coefficient of determination, adjusted and Pred R-Squared and adequate precision values for developed models.

\begin{tabular}{|c|c|c|c|c|c|c|c|c|}
\hline Model No. & St. deviation & Mean & C.V.\% & PRESS & $\mathbf{R}^{2}$ & Adj. $\mathbf{R}^{2}$ & Pred. $\mathbf{R}^{2}$ & Adeq Precision \\
\hline 3.1 & 45.02299 & 408.75 & 11.0148 & 571011 & 0.700902 & 0.157087 & -6.65944 & 5.303137 \\
\hline 3.2 & 0.095284 & 0.585625 & 16.27043 & 1.291315 & 0.557687 & -0.24652 & -4.71916 & 3.208985 \\
\hline
\end{tabular}

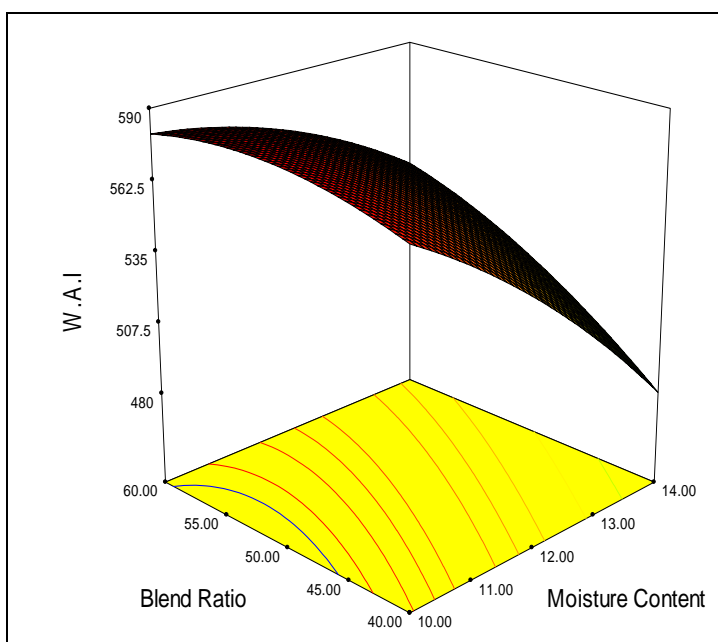

Fig 3.1: Effect of feed moisture content and blend ratio on water absorption index of extrudates

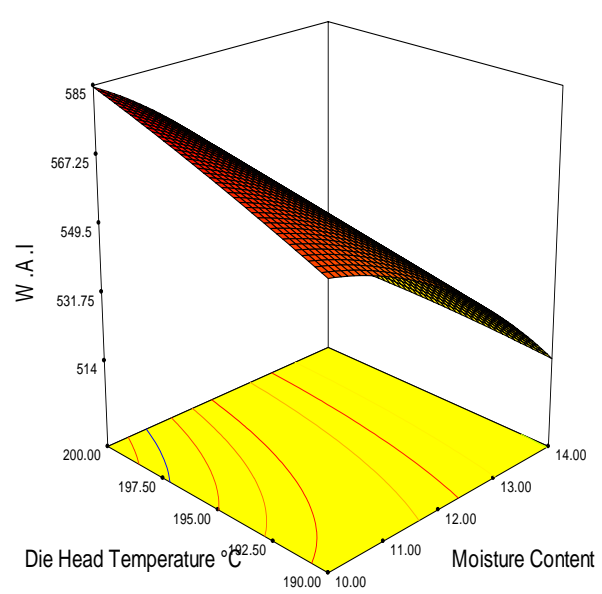

Fig 3.3: Effect of Feed Moisture content and Die head temperature on water absorption index of extrudates

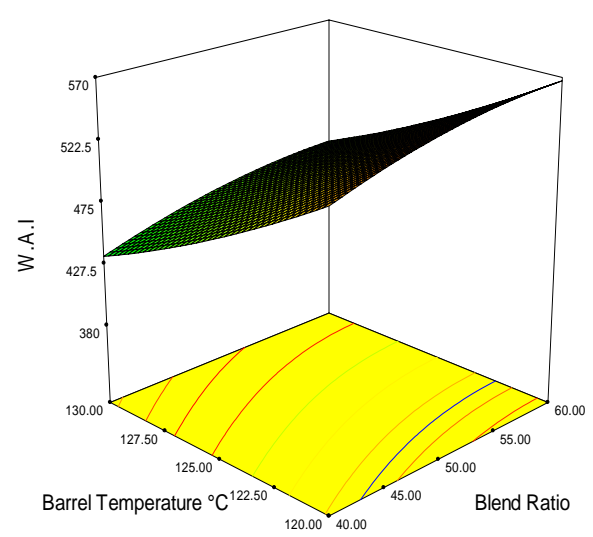

Fig 3.5: Effect of blend ratio and barrel temperature on water absorption index of extrudates

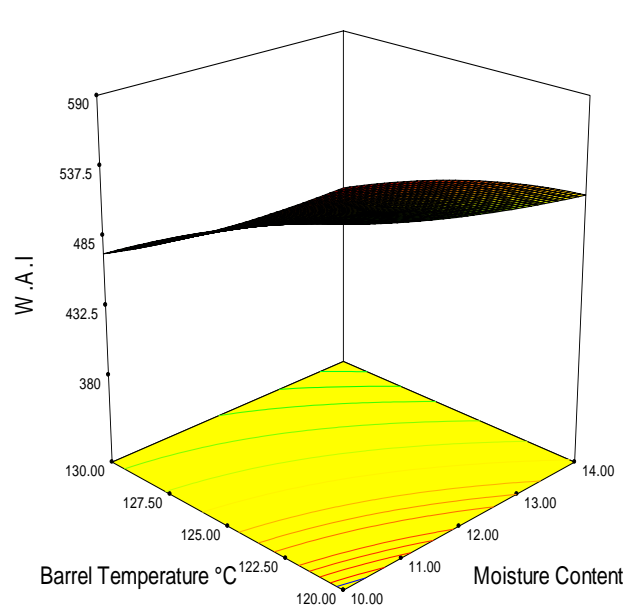

Fig 3.2: Effect of feed moisture content and barrel temperature on water absorption index of extrudates

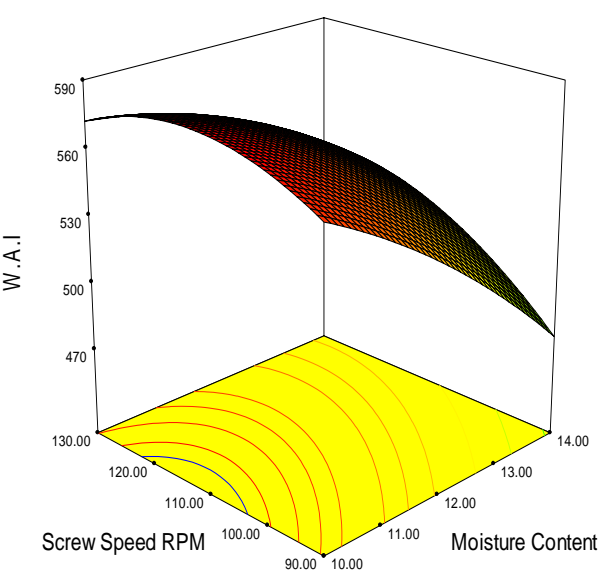

Fig 3.4: Effect of Feed Moisture content and Screw Speed on water absorption index of extrudates

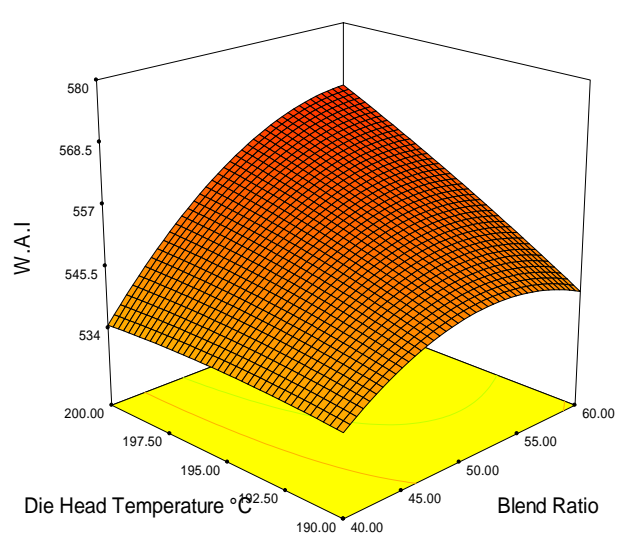

Fig 3.6: Effect of blend ratio and die head temperature on water absorption index of extrudates 


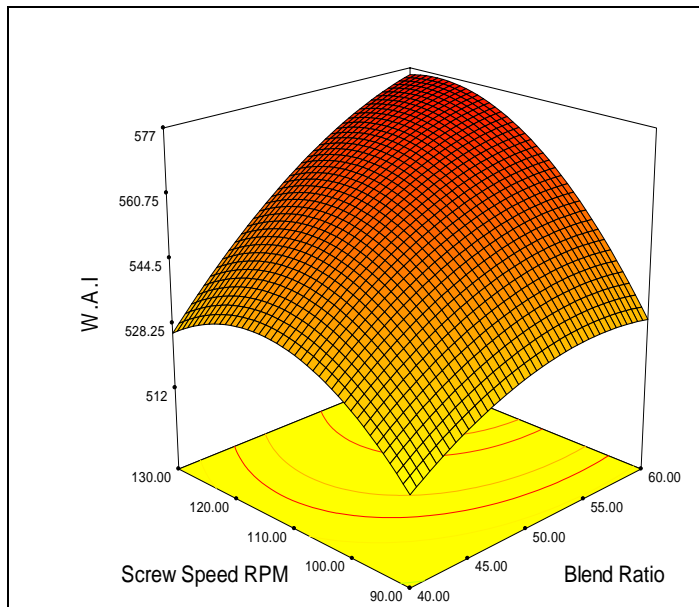

Fig 3.7: Effect of blend ratio and screw speed on water absorption index of extrudates

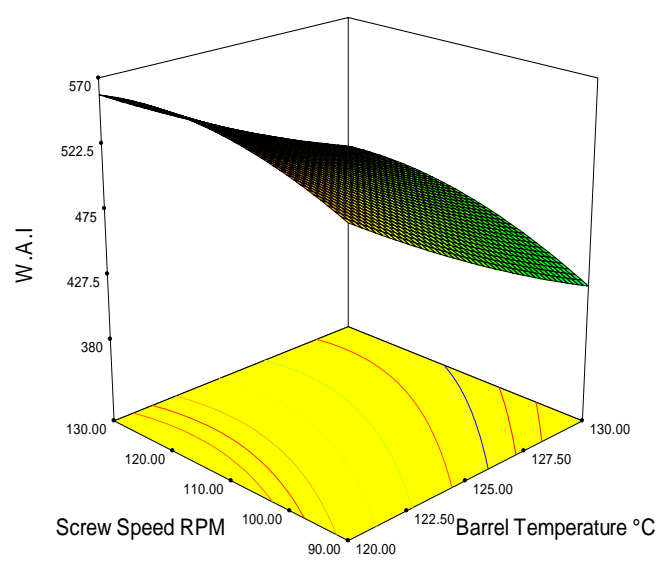

Fig 3.9: Effect of barrel temperature and screw speed on water absorption index of extrudates

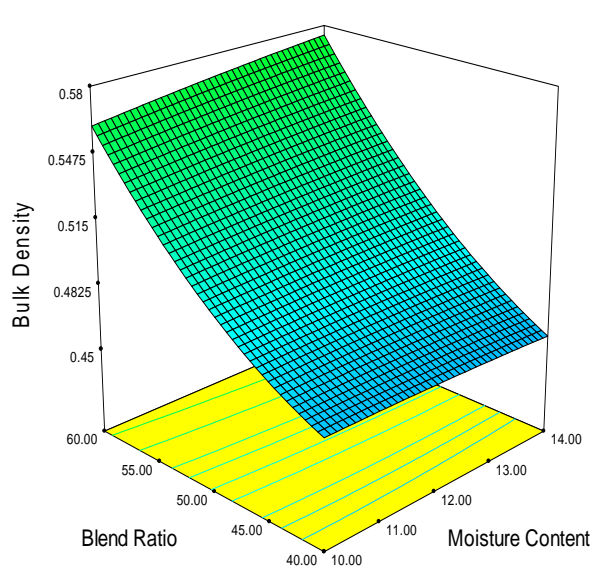

Fig 3.11: Effect of feed moisture content and blend ratio on bulk density of extrudates

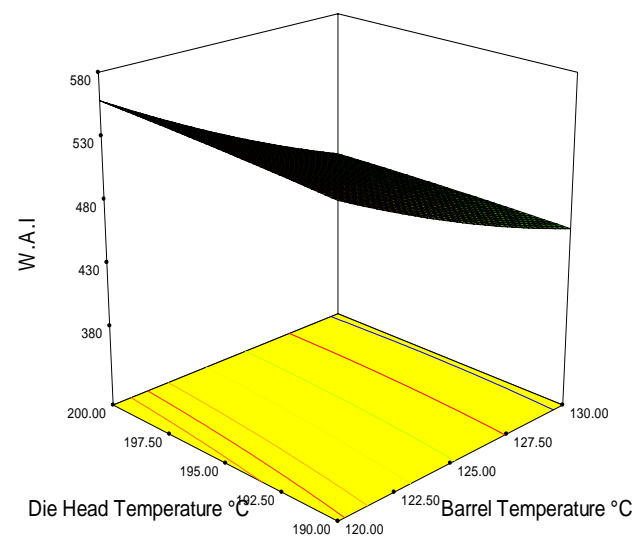

Fig 3.8: Effect of barrel temperature and die head temperature on water absorption index of extrudates

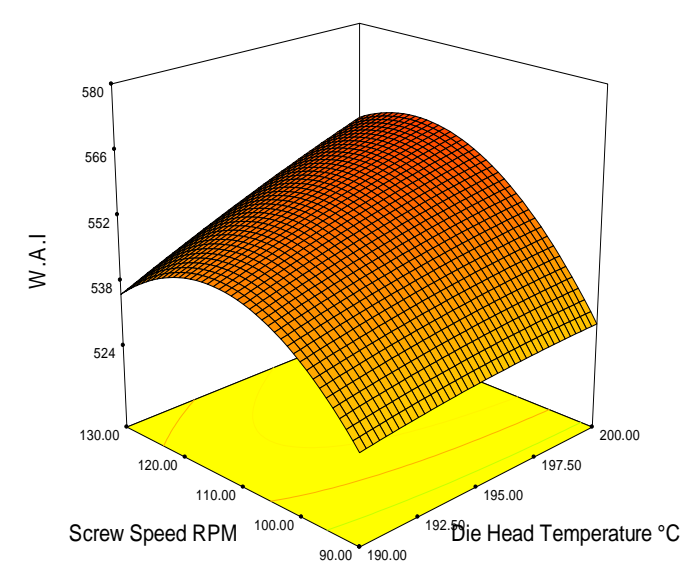

Fig 3.10: Effect of die head temperature and screw speed on water absorption index of extrudates

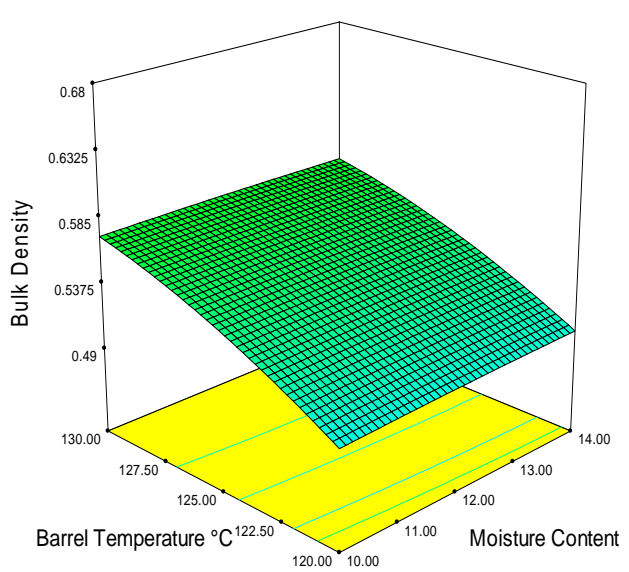

Fig 3.12: Effect of feed moisture content and barrel temperature on bulk density of extrudates

\section{References}

1. Alonso. Effects of extrusion and traditional processing methods on anti-nutrients and in vitro digestibility of protein and starch in faba and kidney beans. Food chemistry. 2000; 68(2):159-165.
2. Ficarella A, Milanese M, Laforgia D. Numerical simulation of cereal extrusion and influence of design and process on the final quality. Tecnica-Molitoria (Italy). 2003; 54(1):9-24. 
3. Della Valle G, Tayeb J, Melcion JP. Relationship of extrusion variables with pressure and temperature during twin screw extrusion cooking of starch. Journal of Food Engineering. 1987; 6:423-444.

4. Garg SK. Influence of processing Parameters on Extrusion Cooked Ready-toEat snack from Defatted SoyRice Blends. Ph. D. Thesis, College of Agricultural Engineering, JNKVV, Jabalpur, 2005.

5. Hardacre AK, Clark SM, Riviere S, Monro JA, Hawkins AJ. Some textural, sensory and nutritional properties of expanded snack food wafers made from corn, lentil and other ingredients. Journal of Texture Studies. 2006; 37(1):94-111.

6. Harper JM. Extrusion of Foods, Boca Raton, FL, CRC Press, Inc, 1981.

7. Iwe MO, Van Zulichem DJ, Ngoddy PO, Ariahu CC. Residence time distribution in a single-screw extruder processing soy-sweet potato mixtures. Lebensmittelwissenschaft und-technologie. 2001; 34(7):478-483.

8. Sanchez Acosta, David Riaz, Mian Richter, Ron Rooney, Lloyd W, Waniska AD, Ralph D. White food-type sorghum in direct-expansion extraction applications, 2004. Texas A\&M University, http://handle.tamu.edu/1969.1/515. 